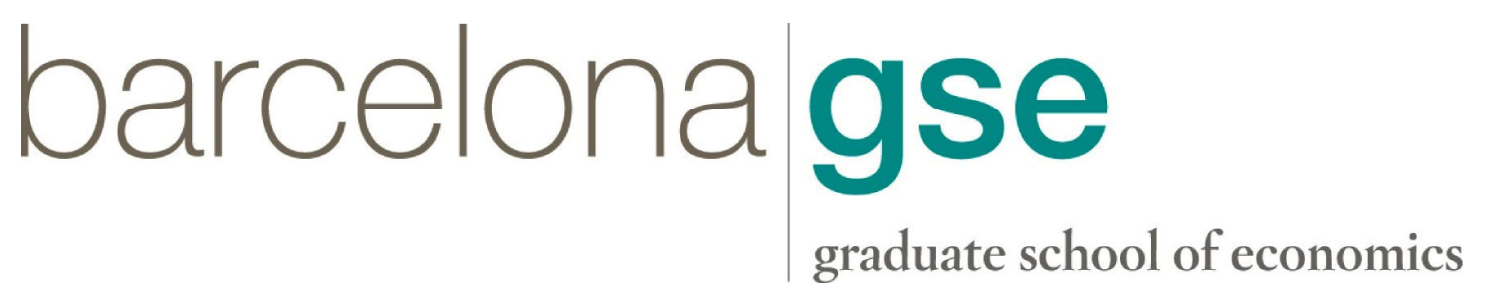

\title{
What do women do? : World population growth and fertility patterns, 1960-2000
}

\author{
Enriqueta Camps \\ Stanley Engerman
}

Revised: January 2010

Barcelona Economics Working Paper Series

Working Paper $n^{\circ} 363$ 


\section{Enriqueta Camps(*) and Stanley Engerman(**)}

\section{What do women do? : World population growth and fertility patterns, 1960-2000.}

\section{ABSTRACT.}

In this paper we attempt to describe the general picture reasons behind the world population explosion during the $20^{\text {th }}$ century. In general we comment that if, according to some, at the end of the $20^{\text {th }}$ century there were too many people, this was has a consequence of scientific innovation, circulation of information, and economic growth, leading to a dramatic improvement in life expectancies.

Nevertheless, a crucial variable shaping differences in demographic growth is fertility. In this paper and by means of panel longitudinal data we identify as important exogenous variables affecting fertility female education levels, infant mortality, and racial identity and diversity. It is estimated that between two and three additional years of schooling for mothers was leading on average (at the world level) to one child less per couple in the period 1960-2000. Even if we can identify a worldwide trend towards convergence in demographic trends, the African case needs to be given more attention, not only because of its different demographic patterns, but also because this is the continent where the worldwide movement towards a higher quality of life has not yet been achieved for an important share of the world's population.

\section{(*) Universitat Pompeu Fabra and (**) University of Rochester and National} Bureau of Economic Reasearch.

Acknowledgments: The results presented here were made possible thanks to the public sponsorship of the Catalan Regional Government and Instituto de la Mujer from the Spanish Ministry of Equality. Jinu Koola, Li Han, and Raquel Graupera Nieto offered inestimable help and assistance in the improvement of the dataset and in the process of yielding statistically significant results. While we make explicit here our acknowledgment of their work, nonetheless we are the responsible for all remaining mistakes. An earlier version was presented at the September 2008 meetings of the Economic History Association where we benefited from the comments of Martha Bailey and also at the September meeting on the EU project on "Unifying the European Experience" organized by Kevin O'Rourke and Steve Broadberry where we benefited from a lot of comments, specially form Albrecht Ritschl and Max Schultze Keywords: Fertility, human capital, infant mortality, race, population growth.

JEL codes: I10, J1,I21, J7, N3 


\title{
Enriqueta Camps (Universitat Pompeu Fabra)
}

\author{
Stanley Engerman (University of Rochester, NBER)
}

\section{What do women do?}

\section{World population growth and Fertility patterns, 1960- 2000.}

\section{Introduction.}

In today's world population growth is regarded as a problem by most of the policymakers and people who deal with social, economic, and demographic topics. This concern, of course, goes back at least to Malthus, and his predictions based on the dynamics of population growth vis a vis economic budget restrictions. At the start of the $21^{\text {st }}$ century prices of some of the basic food products have begun to demonstrate price increases. In general, many people think that if there are too many people now, the situation is going to be even more difficult in the future. Although the price of calories and energy has risen during the last decade, the world is not only increasingly populated but also increasingly industrialized and rich. The answer to the question if there are too many people deserves more attention, since population growth can have negative as well as positive aspects. In the $19^{\text {th }}$ and $20^{\text {th }}$ centuries population growth and the increased population density were considered to be a positive asset for many nations: it could provide for economies of scale, cheaper labor, and the basis for urbanization and economic growth.

In spite of all these worries, about continued population growth, population growth while still positive has been doing so at diminishing rates since 1970. A key question is if there are too many children, with population growth reflecting the high rate of fertility? Or has the population explosion in recent years been due to 
improved health standards and diminished mortality, as a consequence of material prosperity and technological progress?

In this paper we are trying to provide some preliminary data that may be helpful to build the world picture in terms of the variables that influence demographic growth and their regional variance. This is an exploratory paper that intends to frame some of the working hypotheses on the reasons behind demographic growth and its most plausible future evolution. On the basis of preliminary results we hope to be able to model the population dynamics during the second half of the $20^{t}$ century at the world level in forthcoming papers, based on economic, demographic, and cultural factors. These include, in particular, female and child education and employment, infant mortality, and changing income levels, in addition to ethnic differentials. In a very intuitive way we shall first concentrate on the issue of which is the determinant variable behind demographic growth: fertility (and therefore reproductive habits) or mortality (and therefore evolution in health). We avoid here any analysis on nuptiality since in the period under consideration the strength and influence of religion in family formation and the ages of conception of the first child had loosened much of the previous importance it had before 1960 on fertility dynamics.

On the other hand for historical populations, it would be very difficult to find an homogeneous indicator for family formation and nuptiality. Most of the literature and papers on historical demography deal with Europe and the US and therefore with populations that were inside the "European demographic system" (Flinn, 1985) in which conception of children was undertaken by a married and monogamous couple. Indeed most of the statistical calculations on nuptiality and fertility are based on this sort of family arrangement. But when we enlarge the sample to all civilizations and religions of the world we must make some simplifications regarding the culture and motivations behind being married and the conception of children. In some African societies polygamy does exist and the ability to conceive children basically depends on the fertility of the women and not on other social or cultural determinants as in most of Western societies. We want to stress that we are conscious of this limitation, and that when we try to capture 
fertility patterns that are common and statistically significant for all the people of the world, we lose explanatory power. Therefore the questions we put to the data and the results that follow in this introduction are relevant only to fertility patterns that represent the interests of the second half of the twentieth century. We think that the limitations that nuptiality had for the $19^{\text {th }}$ century European demographic system should be relevant in a context in which fertility was expanding and therefore the calculation of the actual available years to conceive by women was a key factor for the level of fertility. As we will see our intent is not to explain which factors prevent female fertility from reaching its potential levels, but just the opposite. We will try to explain the main factors behind the decline in fertility, so that the social factors that prevent attaining the maximum reproductive level, are of secondary importance.

\section{ARE DEMOGRAPHIC PATTERNS CONVERGING ACROSS THE WORLD?}

In the concluding volume to the seminal work on the demographic transition in Europe, Watkins and Knodel and van de Walle (1986) argued that in spite of the existence of sharp differences in the economic achievements of European countries there was a great deal of coincidence in the timing of the demographic transition inside most of the countries of Western Europe. In the European cases of the 19th century, it appears that after a certain threshold level of per capita GDP, epidemics and hunger crisis caused by food scarcity ceased to threaten the population, and adult mortality and infant mortality diminished. More recently, as Becker,et al (2005) indicate over the last half-century convergence in life expectation has occurred, with more rapid increases in countries with initially lower levels and 
with a sharp decline in variation across countries. Thus declines in mortality throughout the world have occurred with more similarity in timing than would be predicted based on economic factors.

At the same time, urbanization and industrial growth brought with it the diminution of legitimate fertility. By means of the diffusion of information that was facilitated by internal migrations, the revolution of communications and the increasing ability to read and write of people, towns increased their influence on the demographic behavior of extended regions and countries (Wrigley,2004; De Vries, 1985 ). This is why, in spite of economic divergence, population dynamics tended to converge. The possibility brought by the transport revolution and migration to exchange information with other people on how the improve health and reproductive practices were among the factors that fostered territorial homogeneity and the diffusion of demographic variables not only in $19^{\text {th }}$ century England but more broadly speaking Eurorpe (Coale and Watkins 1986; Wrigley, and Schofield, 1989, 1997; De Vries 1985; Wrigley,2004). Other authors, using micro historical methods have emphasized the distinctive features of several European regions putting the stress on religious beliefs and socioeconomic variables that may help to explain why regions have similar but not always identical behavior (Brown and Guinenne, 2002) .

Because of its early date, the European demographic transition is unique. In figures 1 and 2 we see that as late as 1960 in the post WW II period, most of the world had high rates of fertility and infant mortality. Therefore by 1960 , during the Golden Age of Capitalism, the demographic regimes still had not experienced any demographic transition in most of the regions of the world. This is particularly true for poor countries or the countries that Jeff Sachs identify as experiencing the tropical pattern of poverty. As late as 1995 this set of tropical countries were among the poorest of the world, and this fact has fostered a long literature on the geographic reasons for economic growth, or its absence, but this is not the issue that most interest, us here. What is important for our argument is that the poorest countries of the world in 1960 (countries in the tropics) were those exhibiting highest rates of fertility and infant mortality. It is plausible to think that in this set of countries the communications and information exchange network we discussed 
before still had to develop in order to make possible the diffusion of fertility and infant mortality decline, innovations that had begun in the developed world.

The world scenario changed significantly however by 2000. Contemporary with the communications revolution, by this date most of the world had moved to modern demographic patterns characterized by, relatively low fertility rates and low infant mortality rates. Therefore the transition from a high fertility (and high infant mortality) regime, a situation in which most of the world exhibits relatively low numbers of children and low infant mortality was achieved in many places by the eve of the twenty-first century. The main deviant from this pattern are the countries of Sub-Saharan Africa. This particular case is striking because not only is this a high fertility region but it is also the region with highest levels of infant and adult mortality. Therefore in this belated demographic transition at the world level there is still a set of countries that remain behind marked by characteristics that seem to limit economic growth. In the Sub Saharan African case, these were not only wars and civil wars, but also hunger and illness (pandemics) leading to death. These help explain the high levels of mortality observed, and also the high levels of fertility with the high probability of death during the first year of life.

In figures and tables we can see the features of the world's regional evolution. Notice in the figures the trend of the variables regarding both fertility and mortality across regions to converge. Even with some delay the most backward regions of the world demographically speaking like Sub- Saharan Africa and South Asia exhibit a trend to converge with the core countries of Europe, North America, and Australia. With this figure we can answer to some of the questions we put in the introduction which are why is world population growing: world population is growing, not because of an increase in fertility levels, but because the improvement of the health conditions of an important set of world countries. In all countries mortality and infant mortality conditions improve, due to by the possibility of most of the world population to live longer and with relatively higher living standards. 


\section{A model of the reasons causing fertility decline.}

The most relevant studies (and the data we present) indicate that fertility and mortality tend to converge in the period under consideration. We have also observed that the relationship between demographic variables and income levels is not linear. When attempting to give forecasts on the levels of future population the variables that seem to be of most concern are changes in fertility (Sachs, 2008; see also UN Human Developent Reports). As said above life expectancies have improved by a considerable amount during the $20^{\text {th }}$ century, in a most remarkable manner until the 1960s, thanks to improvements in nutrition and health achievements (Fogel, 2005). As a general point life expectancies appear to have diminishing returns with respect to income, and Fogel's forecasts is that during the $21^{\text {st }}$ century they are not going to increase by more that 10-15 years (compared with the $20^{\text {th }}$ century in which they nearly doubled). In section 2 we indicated that fertility has a tended to converge at a low level, close to replacement. Africa remained the continent that still has the highest rates. The high fertility rates of poor countries (mainly in Sub-Saharan Africa) remains a matter of concern for the UN. Even if the fertility rates are diminishing, with the present demographic patterns the Net Reproduction Rates indicate that in this group of countries the population should double every thirty years. According to the same source of information if all countries of the world, including Sub-Saharan Africa, achieve fertility rates close to the replacement level, by 2050 the world population should attain a peak of 9.1 billion which is a threshold that most economic authorities hope not to surpass (Sachs, 2008, p. 167).

Therefore the common opinion of demographic planners is that we should try to attain to fertility levels close to the replacement level or below, in order not to undermine world stability. In this section we try to model the factors influencing 
fertility and in the next section we present a regression analysis based on the variables of the model discussed here.

\section{FIGURE 1}

\section{Variables affecting fertility:}
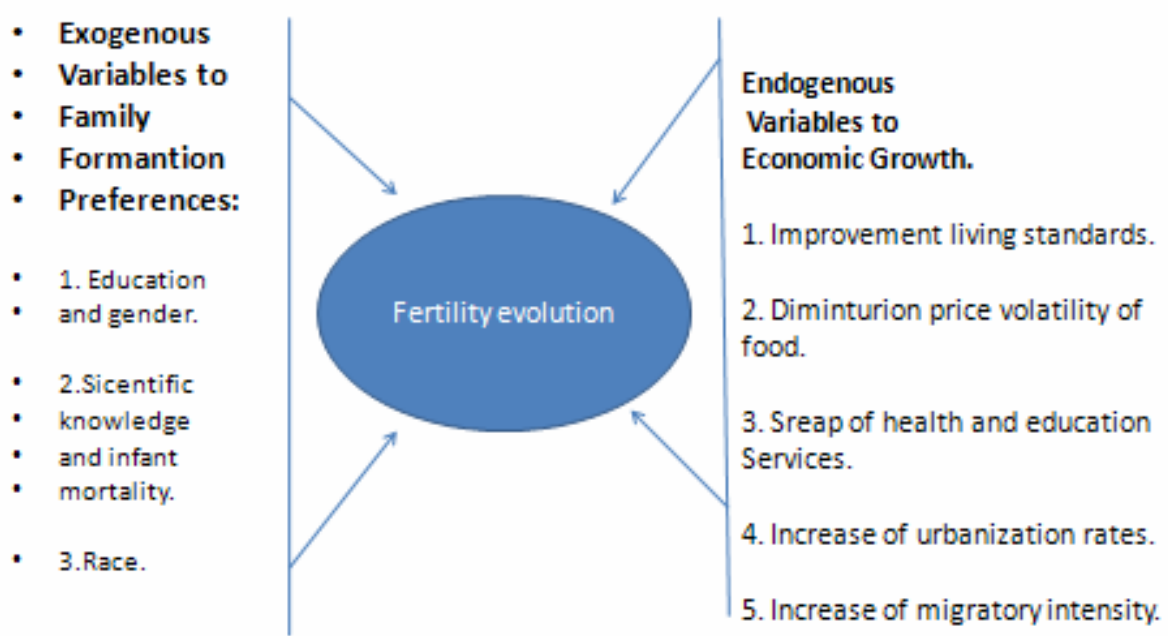

In Figure 1 we divide the variables affecting fertility into endogenous variables and exogenous variables. All endogenous variables are those related to economic growth

and are the main set of variables considered by most of the models dealing with the European Demographic Transition that we have described in section 2. In section 2 we made the point that in spite of there being mechanisms of the diffusion of fertility patterns that were not linked to economic factors, according to most studies of fertility including those dealing with the British Industrial Revolution and its spread over the European continent, the diminution of fertility rates are frequently linked to endogenous factors that might be linked to economic growth: improvement of living standards, urbanization and internal migrations, improvement of the supply of services offering health and education, improvement of agrarian technologies and changes in the prices of food (Wrigley, 
various dates, Wrigley Schofield, De Vries, Knodell et al 1986). Therefore the initial variable we want to look at is the impact on fertility of changes in the level of per capita GDP.

But clearly other exogenous variables that are not directly related to the countries' economic growth can also explain fertility in the poor countries in the decades examined. These variables include: infant mortality, female education, and factors related to race diversity. According to Williamson (1998) infant mortality has played a major role in explaining the fertility changes in countries of East and South Asia in recent decades. For Williamson this variable is exogenous since it mainly depends on the importance of scientific knowledge (vaccines, antibiotics, penicillin, etc) developed by Western World medical innovation power during the $20^{\text {th }}$ century. The sharp effect of the diminution of infant mortality on the increase of the number of surviving children led to a subsequent diminution of total number of births per family, in order to maintain the number of the surviving offspring.

Another exogenous factor influencing the preferences of families to have more or less children is the education level of the mother. According to the data provided by Barro and Lee (2000) on the female/male education ratio (measured by means of the life expectancy of people to continue in the school system according to the regions of the world), the amount of education women receive is culturally shaped and the regions of the world less likely to invest in women's human capital are in East and South Asia (see Boserup,1970; Barro-Lee 2000; Sen, 1990,1992,2003) . But in societies where the families invest in the human capital of women, this can lead to an increase of the value of their paid work (wages) at the expense of the opportunity costs of unpaid housework, like child rearing, child bearing, and other unpaid labor loads. As a consequence of this price unbalance women change their preferences and begin to allocate more time to paid work and less time to reproductive work and other unpaid activities. The last consequence of all what we have said is that fertility should diminish and female participation levels increase (Galor, Weil, 1996; Dreze and Sen, 1995; Caldwell, 1982). Most interestingly, more educated women not only produce less children but also higher quality of children 
(Becker, 1991). In poor countries the effects of the education of the mother on the health and education of the children have been successfully outlined by the literature (Le Vine et alt, 1991, Baizan, Camps, 2007).

A third exogenous factor is race. While differences in the demographic patterns according to race are narrowing as it has been proved by the convergence of mortality rates of black and whites in the US during the second half of the $20^{\text {th }}$ century (see the table) in some parts as a consequence of the democratization of the supply of public goods, such as water sanitation and other health services (see Troesken, 2004), as well as some convergence in income levels.

In the following section we present 2 models. The first is presented in order to identify the relevant variables to explain the evolution of fertility at the world level, using the variables previously described. Since there is a considerable difference in the numerical magnitude of the variables the model is presented in 2 ways: in absolute numbers multiplying the values of fertility and infant mortality per 1000 and in logarithmic terms. In the second model we present the variables affecting the gender gap since women's education shall appear as one of the main factors that can lead to the reduction of fertility.

\section{The empirical results on variables affecting fertility.}

In table we present the results of regression 1. Regression 1 is based on panel of data for 138 countries of the world for which we have continuous information every five years in the period 1960-2000. The total number of observations is 805 and we avoid here country fixed effects since some variables as race or the ethnic fractionalization are constants. The variables we include in this linear regression are per capita GDP, population size, infant mortality, the interaction of infant mortality with brown and indian races, the interaction of infant mortality with black population, female education, ethnic fractionalization, the effects of ethnic composition, and time effects. 
The most significant results of the table are the very low explanatory power of levels of income (per capita GDP) and the very high impact of infant mortality and women education. Taken into account that the dependent variable is fertility rates*1000 the impact of income is nearly nil. From this finding we can imply that the impact of variables endogenous, associated with economic growth (such as those presented in the diagram: living standards, urbanization, internal migrations, services supply) are nearly irrelevant to explain the evolution of fertility during the second half of the $20^{\text {th }}$ century. This may be because in this stage, most (of course not all) of the countries already have achieved the minimum supplies of health services and other public goods that are significant of the modern world of the $20^{\text {th }}$ century, like water sanitation, well established transports and communication networks, basic agrarian technologies to avoid price volatility of foodstuffs. It also may be caused to the fact that in the period here under consideration, the world has been increasingly globalised in communications and transportation and therefore the human capital diffusion factors that were so important for describing the spread of the Demographic changes in Europe were already established at the world level during the second half of the $20^{\text {th }}$ century. Indeed in model 2 of the $2^{\text {nd }}$ regression (Table 5) we obtain the result that the share of urban population at the country level has very significant effects on fertility. In figure 1, inspired in the literature dealing with $19^{\text {th }}$ century European demographic transition, we stated the conclusion the urbanization rates could be considered endogenous to economic growth. But this may not be truth in the second half of the $2^{\text {th }}$ century when countries of the Third World began to exhibit high rural to urban migration flows and high levels of urbanization. According to model 2 of table 5 urbanization rates are very significant to explain variations of fertility levels showing the further implications that the availability of information that towns and cities make possible have on the diffusion of new fertility patterns.

Therefore, if income is not the relevant variable, which are the really significant variables? According to our model the relevant variables are those presented 
above as exogenous to the family formation preferences: infant mortality, female education, and race (particularly the difference between black and white). The increase of 1 point of infant mortality rates has as a result the increase 0.012 in the number of children per woman. The increase of 1 year in the length of women schooling has as a result a reduction in 0.361 in the number of children of that women. Blacks had higher fertility levels, above those of the brown or India populations. Nonetheless when we interact the variable being black by the infant mortality we see that this combination has a negative result on fertility levels. This fact may be caused by the negative effect on fertility brought by extraordinary mortalities caused by civil wars and pandemics in Africa South of the Sahara. These mortality epidemics and war have as an effect the imbalance of the sex ratio at the country level or the impossibility for many women to have children because of the diffusion of illnesses like AIDS.

From our results we can conclude that if we want to diminish fertility levels of Africa South of the Sahara and other poor countries the way to do this is by improving infant mortality conditions by means of scientific medical innovations that allow for the eradication of pandemics like AIDS, HIV, or malaria. These epidemic mortalities affect people of all ages and, as a matter of fact, are among of the reasons why people don't act according to expectations to be better off in the future. High levels of infant mortality also mean that surviving children are only a limited number of those born.. Therefore many women will conceive a lot of children in order to ensure that some of them will survive to adulthood and then they can offer some support to the family when the parents grew old.

Another result is the impact of female education on fertility levels. In table 6 we present results relating to the variables affecting the gender gap as female/male earnings at the world level. We only have results on the variables for this second model for the year 2003, and therefore the regression is just a cross section across countries. But the results are significant. This is a very important implication if we want to control the levels of fertility, as has been done in the recent past in 
countries like China and India. In maps presented in section 2 you can observe that in both countries the levels of fertility have diminished sharply in the decades from 1960 to 2000, mainly because of policies of family planning exogenously imposed on couples. Since these societies are very biased regarding gender, the result of policies like the 1 child policy in China has been the increase of girls' infant mortality relative to boys, in sharp contrast to what happen in the rest of the world. We don't mean that this fact suggest the practice of infanticide in this countries. But if the couple wants a boy and the policy restricts the number of children per couple to one, then if the first born is a girl the main consequence is that parents want to deliver her in adoption or as in the case of Taiwan to a minor marriage. All these mean an increase of the levels of infant mortality of girls relative to boys, as several research projects suggest. This is an important externality of family planning policies that is clearly observable on these maps and politically these should be avoided in future demographic programs aiming at diminishing fertility levels and population growth.

As a final remark, we think it is important to realize what we have tried to stress several times in this paper: the link between income and fertility is not linear and many exogenous variables like medical and scientific improvements, or gendered cultural biases or racial identity also have an important role on the evolution of fertility. As stated in the introduction in this paper we have just tried to define which and why these variables are important. Anyway, it is worth noting here that if in section 2 we have observed that fertility patterns have a world converging trend in the period under study (1960-2000), the exogenous variables we have dealt with here also tend to converge. While the trend of world living standards to converge has also been stressed by some authors (Sala-i-Martin, 2005) this remains a source of intellectual discussion (Becker, 2005; Williamson,2001; Engerman and Sokoloff, 2002, 2005). 


\section{CONCLUSION}

In recent years there has been some common movement in a number of demographic variables in most parts of the world, although substantial differences in levels of these variables remain. What is perhaps most interesting is the similarity in timing of these movements in fertility and mortality rates, and in the various related explanatory factors such as infant mortality rates, years of schooling of females, female labor force participation, and the relevant economic factors. The similarity in timing of change raises question about the importance of country specific factors as opposed to those influenced by broader cross-country and international forces. This, of course is not a new point, as seen in the discussion of the European Fertility Transition in the late nineteenth century and, among the behavior of various ethnic groups in the U.S., the similarity of movements in mortality of the black and white populations in the twentieth century. The basis of this similarity, whether due to technological externalities, external effects in communication of ideas, to diffused changes in tastes, or to direct intervention of international agencies or foreign countries, may be debated as can be the evaluation in of globalization and cross-country connections. Another cause of changing fertility and mortality patterns has been the existence of civil wars and international warfare, which have a rather long and continuous history. The deaths in Africa due to warfare in the past half century have been estimated to be over 15 million, although warfare plus diseases in Sub-Saharan Africa have been consistent with a pattern of basically unchanged fertility to 1990, with only a moderate decline in the next decade. The regions of Sub-Sahara African and South Asia do, however, have the highest fertility, although declining in recent years, as well as the lowest female literacy rates, but rather different female labor force participation rates. The relation of fertility rates to the degree of inequality requires more study, but it is probable that the degree of inequality raises fertility.

Among the worldwide trends in the second half of the twentieth century has been the increase in year of schooling of women and their labor force participation 
rate, something that many expect to lead to a decline in fertility because of the increased value of a woman's time and the effect this has on the cost of childbearing. This is clearly the predicted pattern for developed economies, where female labor force increases reflect an improvement in opportunities available to women, and also permit declines in child labor in order to increase their education. This relation, however ,has been u-shaped (Goldin, 1994), since women's labor force participation is also very high when income levels are low and labor is needed from women or children to support the family at low levels of income. SubSaharan Africa has had high rates of female labor force activity, low rates of female schooling and literacy, and yet high rates of fertility which we can interpret as a consequence of the other important variables shaping fertility according to our analysis which is high rates of infant mortality. And, unlike other areas, it presents both high female labor force participation and high child labor force activity. We are thus back to the long-standing issue of policy towards some developing nations, how can we determine what actions to take, who should become the major agents of change, and what is the feasible time period within which to accomplish those goals. 


\section{FIGURE 1}

Fertility Rate in 1960 (number of children per woman)

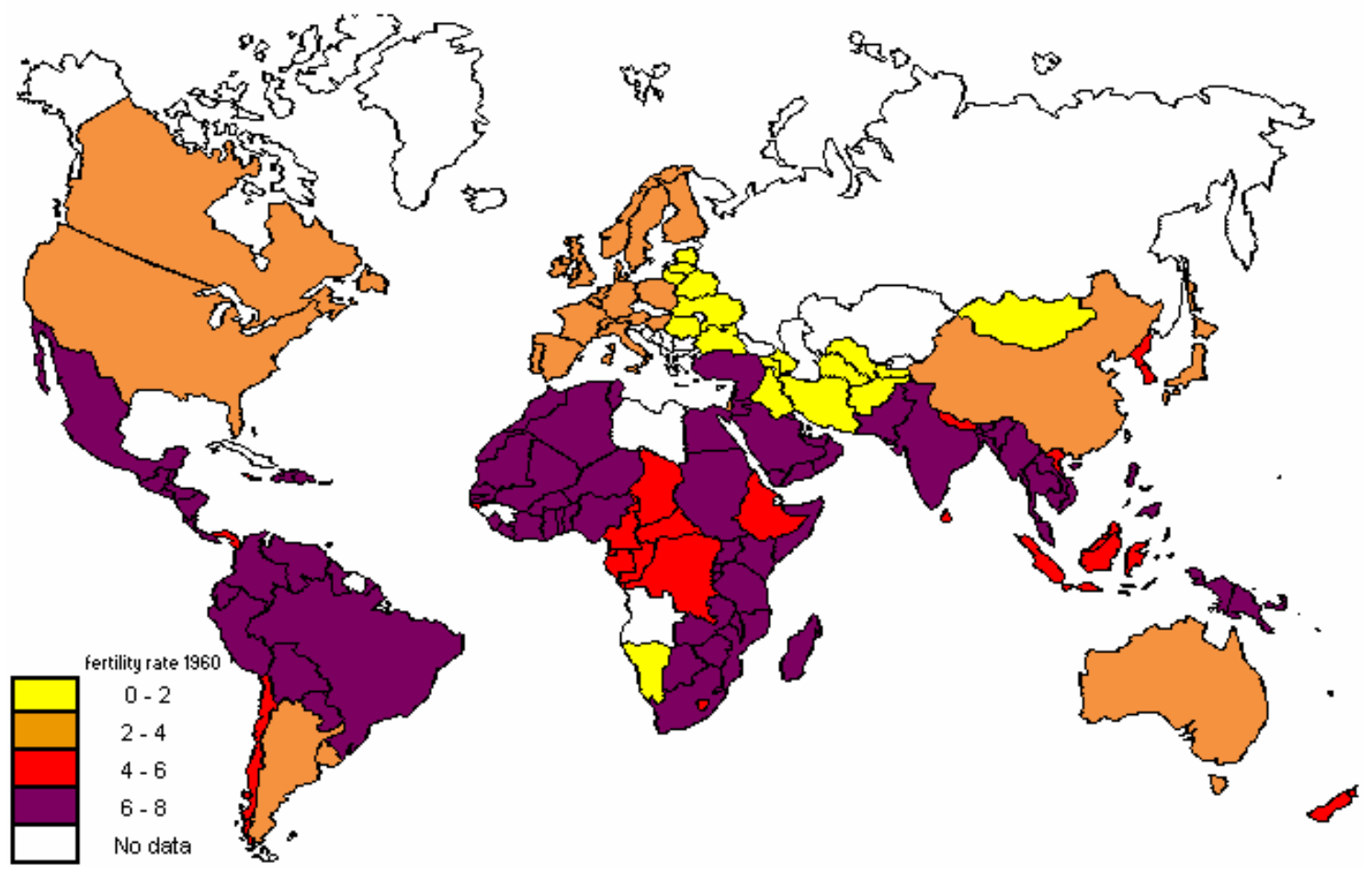




\section{FIGURE 2}

Fertility Rate in 2000 (number of children per woman)

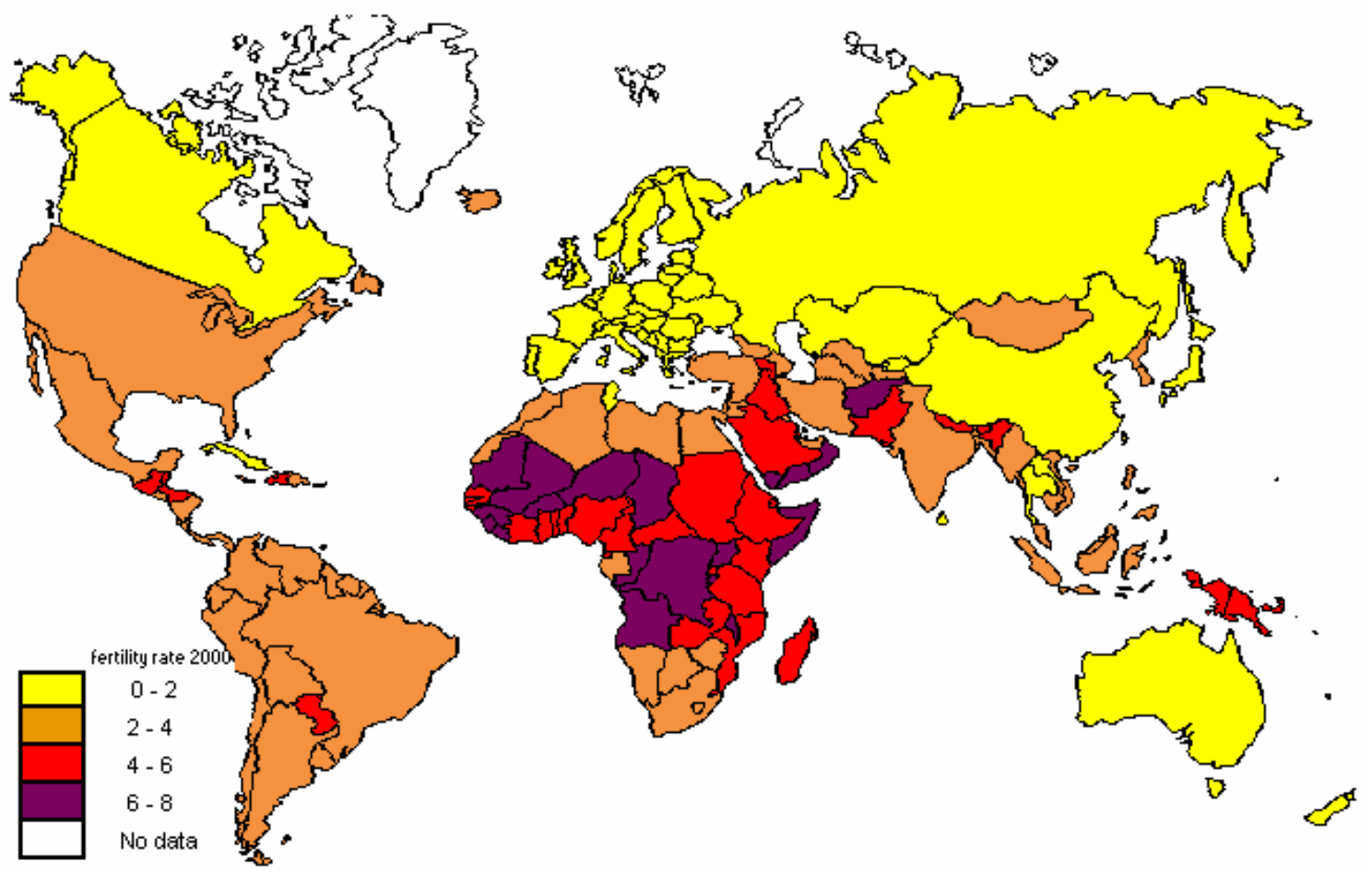

Data Source: World Bank Datasets. 


\section{FIGURE 3}

Infant Mortality Rate in 1960 (ages 0-1)

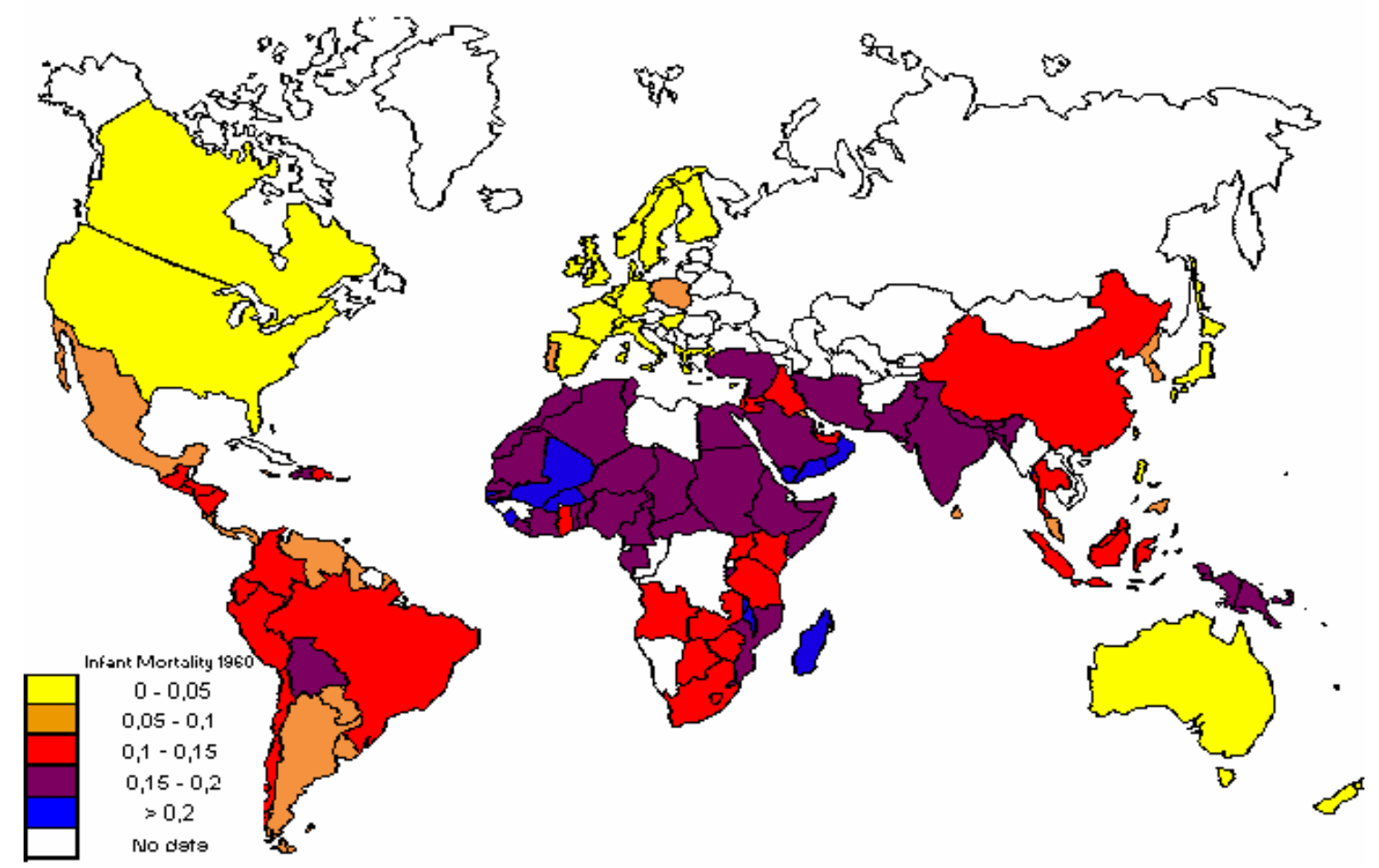

Data Source: World Bank Datasets. 


\section{FIGURE 4}

Infant Mortality Rate in 2000 (ages 0-1)

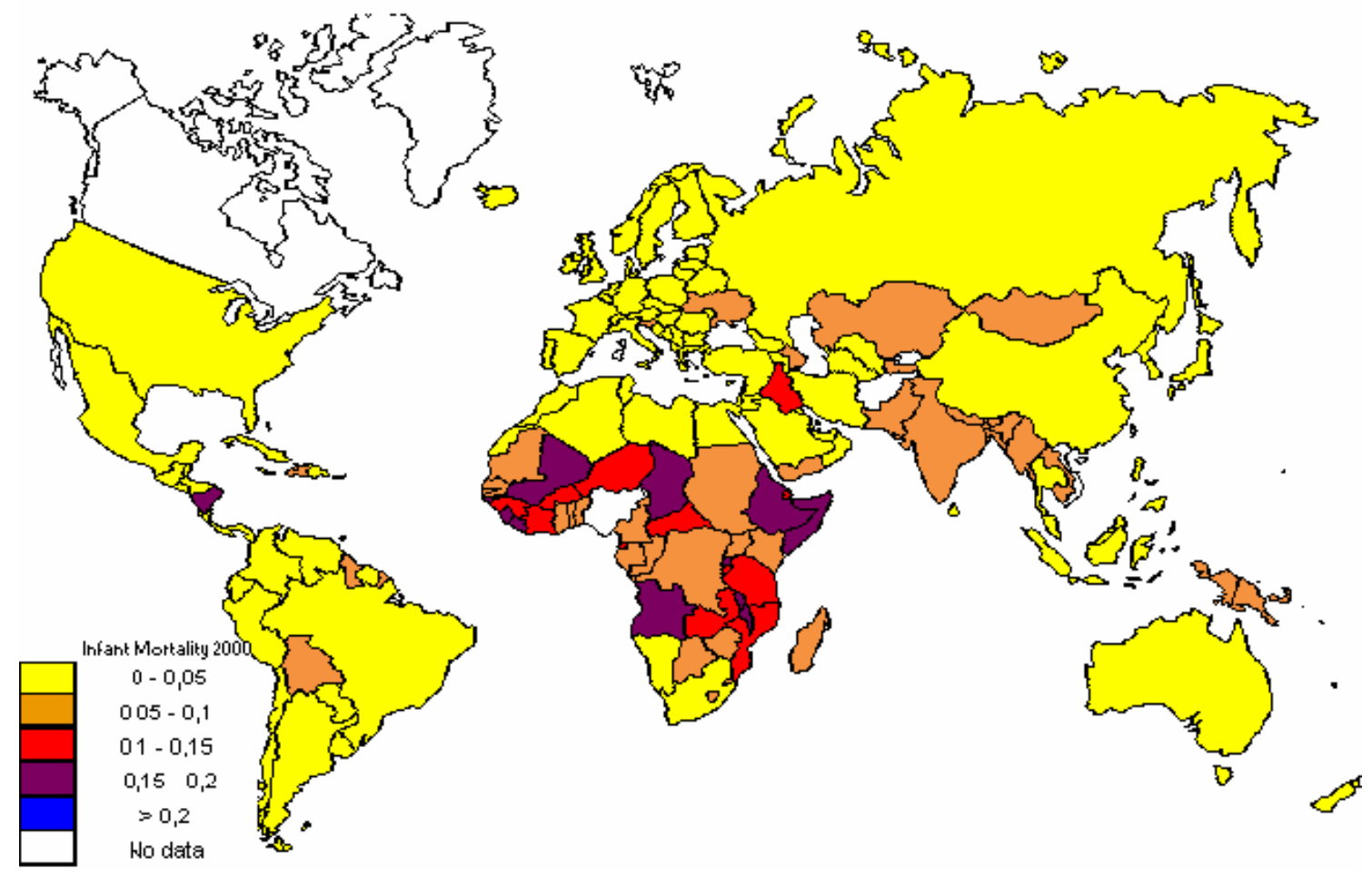

Data Source: World Bank Datasets. 
FIGURE 5

Female labor participation in 2000

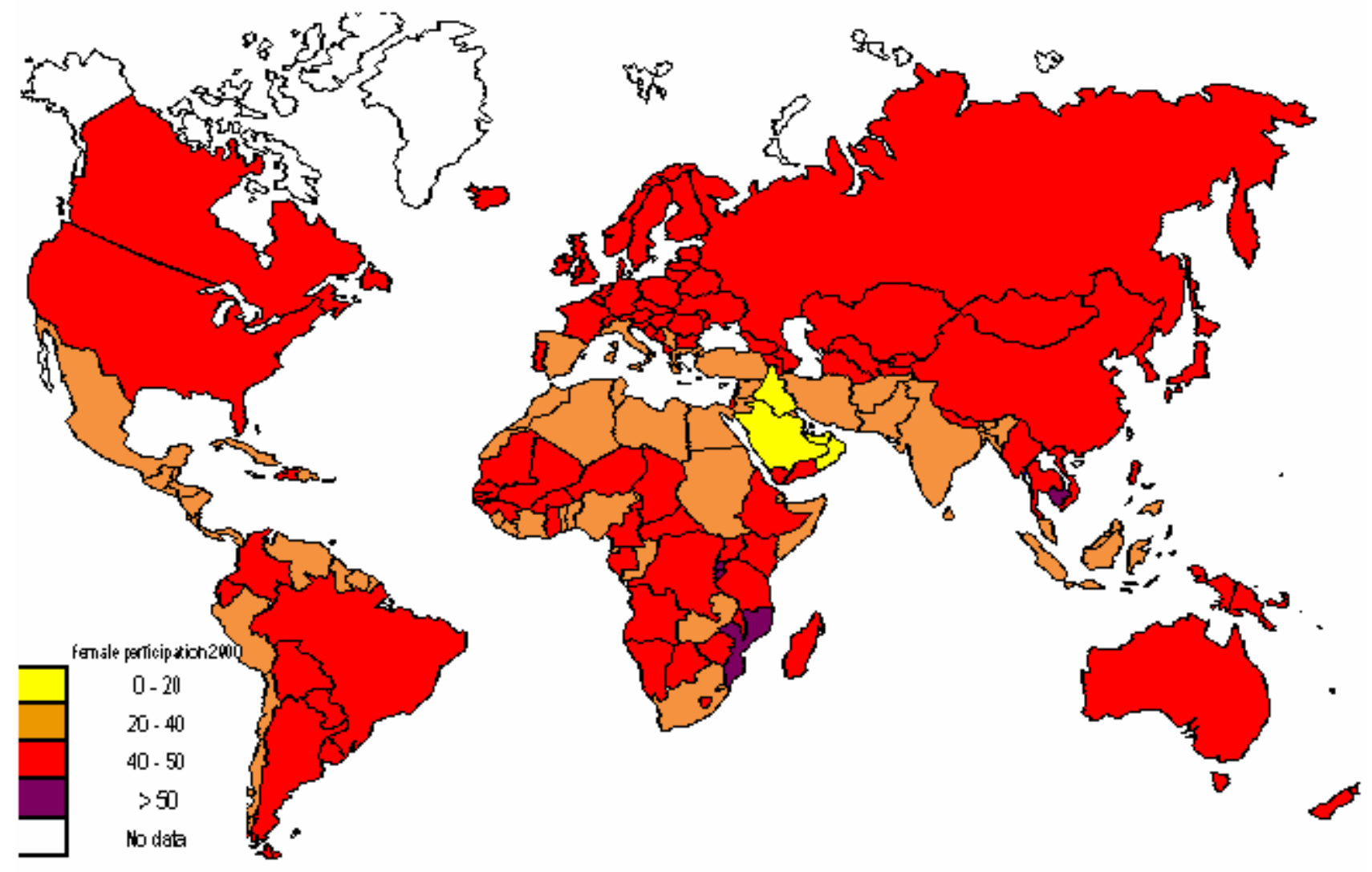


table 1a. Mean fertility by region, 1960

\begin{tabular}{lcccc}
\hline Fertility 1960 & Mean & Std. Dev. & Min & Max \\
\hline OECD & 2.99 & 0.93 & 2.17 & 6.28 \\
Sub Saharan Africa & 6.41 & 0.82 & 4.06 & 8 \\
Latin America & 6.17 & 1.22 & 2.87 & 7.35 \\
Central Asia \& Middle East & 6.82 & 1.22 & 3.87 & 7.75 \\
South Asia & 6.31 & 0.75 & 5.27 & 6.98 \\
East Asia-Pacific & 5.18 & 1.52 & 2.04 & 6.97 \\
non-OECD Europe & 2.82 & 0.59 & 2.02 & 3.44 \\
North Africa & 7.16 & 0.13 & 7.03 & 7.34 \\
\end{tabular}

Table $1 \mathrm{~b}$ : Mean fertility by region, 2000

\begin{tabular}{lcccc}
\hline Fertility, 2000 & Mean & Std. Dev. & Min & Max \\
\hline OECD & 1.65 & 0.28 & 1.23 & 2.16 \\
Sub Saharan Africa & 5.33 & 1.37 & 1.85 & 7.64 \\
Latin America & 2.90 & 1.03 & 1.64 & 6.08 \\
Central Asia \& Middle East & 3.33 & 1.44 & 1.38 & 7.05 \\
South Asia & 4.44 & 1.57 & 1.98 & 6.85 \\
East Asia-Pacific & 2.67 & 1.14 & 0.94 & 5.21 \\
non-OECD Europe & 1.45 & 0.28 & 1.1 & 1.95 \\
North Africa & 2.91 & 0.68 & 1.96 & 3.71 \\
\hline
\end{tabular}

Source: see figure 1 
Table 2a. Mean infant mortality rates by region, 1960

\begin{tabular}{lcccr}
\hline IMR, 1960 & Mean & Std. Dev. & Min & Max \\
\hline OECD & 0.04 & 0.04 & 0.003 & 0.18 \\
Sub Saharan Africa & 0.17 & 0.03 & 0.068 & 0.219 \\
Latin America & 0.10 & 0.04 & 0.05 & 0.19 \\
Central Asia \& Middle East & 0.14 & 0.05 & 0.031 & 0.212 \\
South Asia & 0.15 & 0.05 & 0.069 & 0.186 \\
East Asia-Pacific & 0.07 & 0.05 & 0.02 & 0.163 \\
non-OECD Europe & 0.06 & 0.02 & 0.03 & 0.088 \\
North Africa & 0.17 & 0.01 & 0.158 & 0.178 \\
\hline Table 2a. Mean infant mortality rates by region, 2000 & & & \\
\hline IMR, 2000 & Mean & Std. Dev. & Min & Max \\
\hline OECD & 0.01 & 0.01 & 0.003 & 0.038 \\
Sub Saharan Africa & 0.09 & 0.04 & 0.012 & 0.167 \\
Latin America & 0.03 & 0.03 & 0.0072 & 0.159 \\
Central Asia \& Middle East & 0.04 & 0.03 & 0.006 & 0.102 \\
South Asia & 0.06 & 0.02 & 0.016 & 0.081 \\
East Asia-Pacific & 0.04 & 0.03 & 0.0029 & 0.095 \\
non-OECD Europe & 0.02 & 0.02 & 0.0041 & 0.08 \\
North Africa & & 0.01 & 0.017 & 0.041 \\
\hline & & & & \\
\hline
\end{tabular}




\section{FIGURE 6}

Figure 1. Trends in total fertility rates by region, 1960-2000

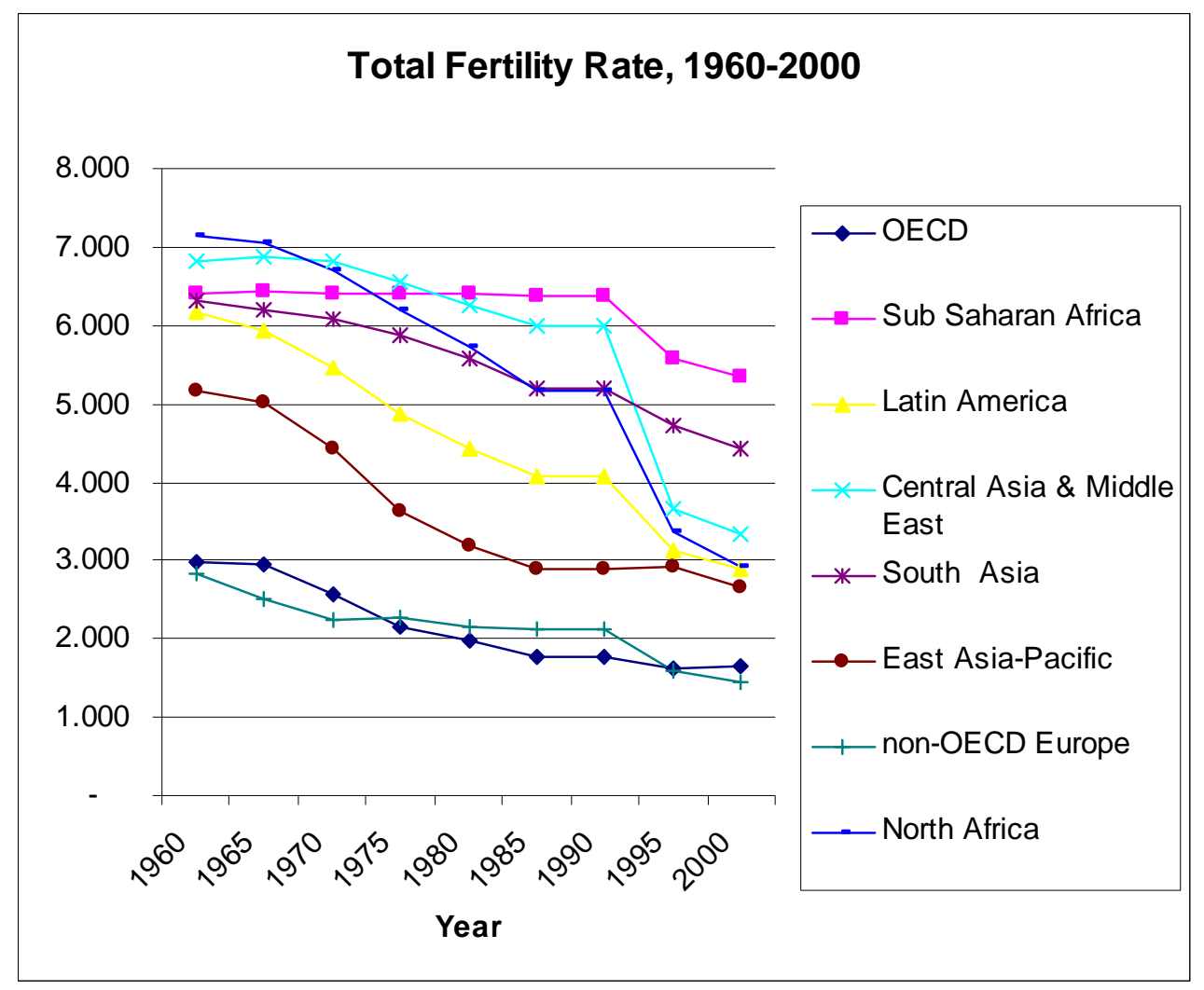

Source: World Bank Datasets. 


\section{FIGURE 7.}

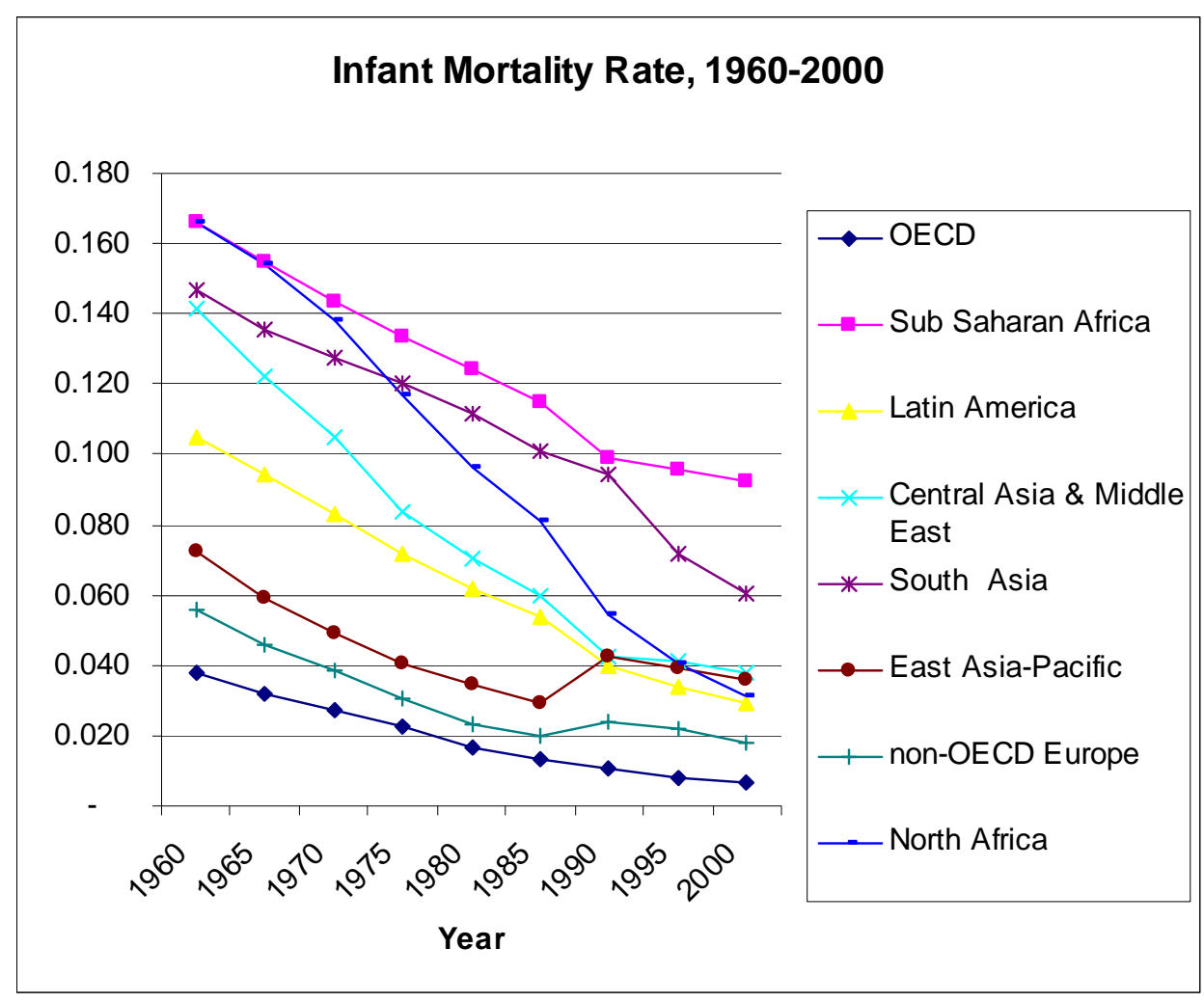

Source: World Bank Datasets. 


\section{TABLE 3: MORTALITY AND RACE; 20TH CENTURY US}

$\begin{array}{ccc}\begin{array}{c}\text { Evolution of life expectancies at birth(male) } \\ \text { White }\end{array} & \text { Black } & \text { Difference (absolute) (years) } \\ 48 & 33 & 15 \\ 56 & 47 & 9 \\ 63 & 52 & 11 \\ 68 & 60 & 8 \\ 73 & 64 & 9 \\ 74 & 67 & 7\end{array}$

\section{Evolution of infant mortality:}

$\begin{array}{rcc}\text { White } & \text { Black } & \text { Difference (absolute) (years) } \\ 98.6 & 181.2 & 82.6 \\ 60.1 & 99.5 & 39.4 \\ 43.2 & 72.9 & 29.7 \\ 22.9 & 44.3 & 21.4 \\ 10.9 & 22.2 & 11.3 \\ 6.0 & 14.3 & 8.3\end{array}$

Source: Carter,et al, Historical Statistics of the United States, Volume 1. 


\section{TABLE 4.}

THE VARIABLES AFFECTING FERTILITY AT THE WORLD LEVEL, 1960-2000.

Panel Regression Analysis with time fixed effects.

Dependent variable: Fertility rates*1000.

(1)

(2)

Per capita GDP

Population

Infant Mort*1000

Infant $\mathrm{M} *$ Black *1000

Female education

(in years in school)

Ethnic fractionalization

Indian

Black

1965

1970

1975

1980

$$
\begin{array}{r}
0.0000265 \\
(0.0000677)
\end{array}
$$

$-0.0015422$

(0.0004781)*

12.109

$$
(1.360017)^{* * *}
$$$$
0.6969
$$$$
\text { (0.0530071) }
$$$$
-0.122419
$$$$
(0.019187)^{* * *}
$$

$-361.6868$

$(25.011)^{* * *}$

758.9162

(332.07)

$$
0.0688
$$

(7.20297)

14.46389

$$
(2.737671)^{* * *}
$$

$$
-48.3319
$$

(87.09409)

$$
-206.2265
$$

(88.39939)

$-384.8179$

$$
(90.760)^{* * *}
$$

$-388.7844$
0.0001909

$(0.000085)^{* *}$

$-0.0015061$

$(0.00087)^{*}$

11.668

$(1.5537)^{* *}$

0.05965

(0.05524)

$-0.143567$

$(0.02145)^{* * *}$

348.573

$(36.063)^{* * *}$
$-58.57068$

(86.379)

$-227.158$

(89.8002)

$-412.7802$

$(96.1796)^{* * *}$

$-413.858$ 


$\begin{array}{lll} & (95.98228)^{* * *} & (108.9102)^{* * *} \\ 1985 & -437.7118 & -465.7858 \\ & (101.6275)^{* * *} & (121.2548)^{* * *} \\ 1990 & -197.8845 & -232.8886 \\ & (109.7197)^{* *} & (138.9787)^{*} \\ 1995 & -721.3549 & -736.1902 \\ & (117.525)^{* * *} & (154.081)^{* * * *} \\ 2000 & -651.1294 & -661.2506 \\ & (125.974)^{* * *} & (172.2096) \\ \text { CONSTANT } & 5059.169 & 5936.185 \\ & (227.0499) & (178.3941) \\ N= & 805 & 805\end{array}$

R Squared within $=0.717$; between $=0.8181$; overall $=0.7904$

Wald Chi2 (17) $=2211.21$

Data source: data on per capita GDP, Population and female human capital are from Barro Lee 138 countries dataset for years 1960-85, and had been updated for years 1985-2000 by means of the World Bank Datasets. Data on Fertility and Infant Mortality come from the World Bank. Data on ethnicity com from Alberto Alesina dataset. The aggregation from ethnicity to racial groups (black, Indian...) has been done aggregating Alesina's data. This work was done by means of RA of two students from Harvard, Will Nygard and Carmen Madanes during the leave of Enriqueta Camps at that university in years 2005-2006. 


\section{TABLE 5.}

PANEL REGRESSION OF VARIABLES AFFECTING FERTILITY. TIME AND COUNTRY FIXED EFFECTS. DEPENDENT VARIABLE: Fertility rates*1000

(1)

Per capita GDP

Population

Share Urban Population

Infant mortality(t)*1000

Infant mortality(t-10)*1000

$(2.247994)^{* * *}$

InfMort*1000*Indian

InfMort*1000*black

Years in school of women

$(2.8569)^{*}$
(2)

$-0.0000178$

$(0.0000545)^{*}$

$-0.00209229$

$(0.0003575)^{* * * *}$

$-4404.836$

$(2548.748)^{*}$

13.3975

$(1.7528)^{* * *}$

$-0.08272$

$(0.031998)^{* * *}$

$-0.056054$

$(0.016354)^{* * *}$

$-446.2092$

$(27.87684)^{* * *}$

Ethnic fracc*infant*1000

$-18.58352$

$(4.213791)^{* * *}$

Female school/male sch $\quad-1180.001$

$(294.6223)^{* * *}$

1975

$-205.638$

(77.48136)*

1980

$-301.3689$

$(83.42634)^{* * *}$ 
1985 $-381.667$

$$
(92.42747)^{* * *}
$$

1990

$-230.7394$

(104.2312)

1995

$-836.1126$

$(114.0434)^{* * *}$

2000

$-873.9912$

$(127.2808)^{* * *}$

Constant

4534.716

(316.2808)

Time fixed effects

$1,310.52$

Country Fixed Effects

N

R squared within $=0.6636$

$R$ Squared between $=0.643$

R Squared overall $=0.5962$

$F(13,521)=79.02$
498.9763

632.00
5479.544

$(220.803)^{* * *}$

384.2125

764

R squared within $=0.6987$

$\mathrm{R}$ squared between $=0.7819$

R squared overall $=0.7551$

Wald chi2(7) $=2185.03$

Data Sources: the same as in table 4. 


\section{FIGURE 8}

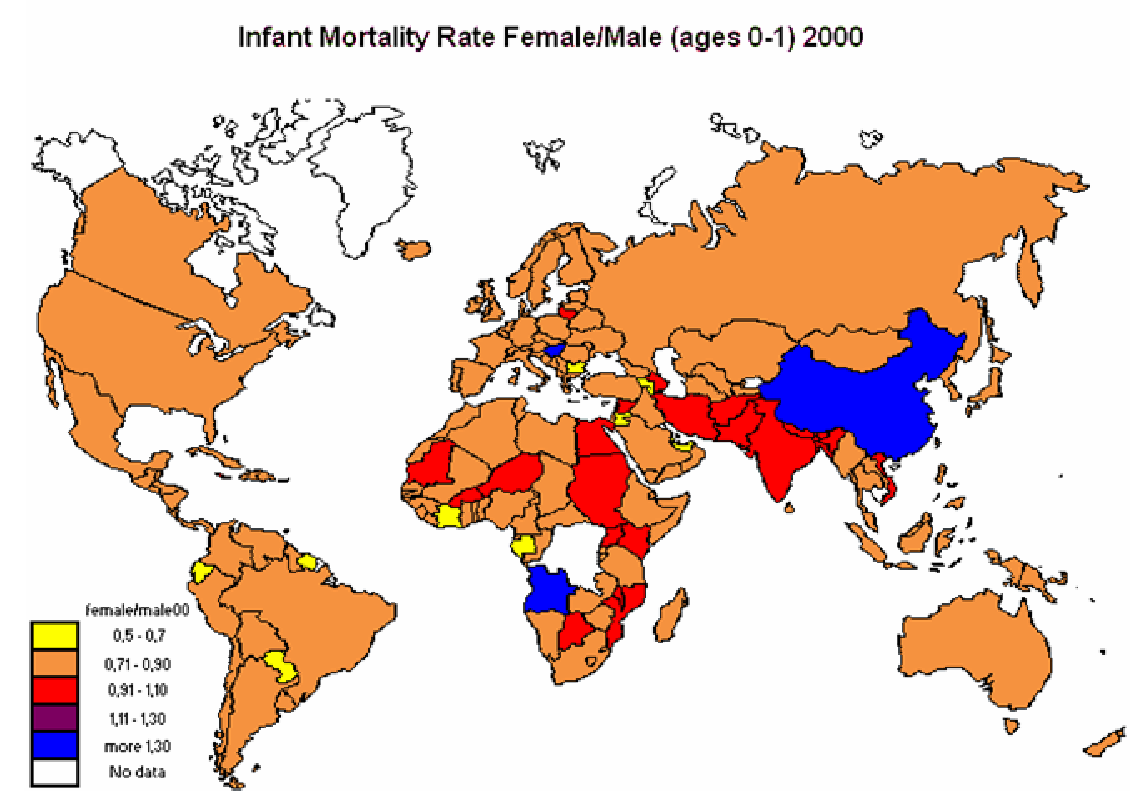

Data source: World Bank Dataset. 


\section{FIGURE 9}

Income Female / Income Male 2003

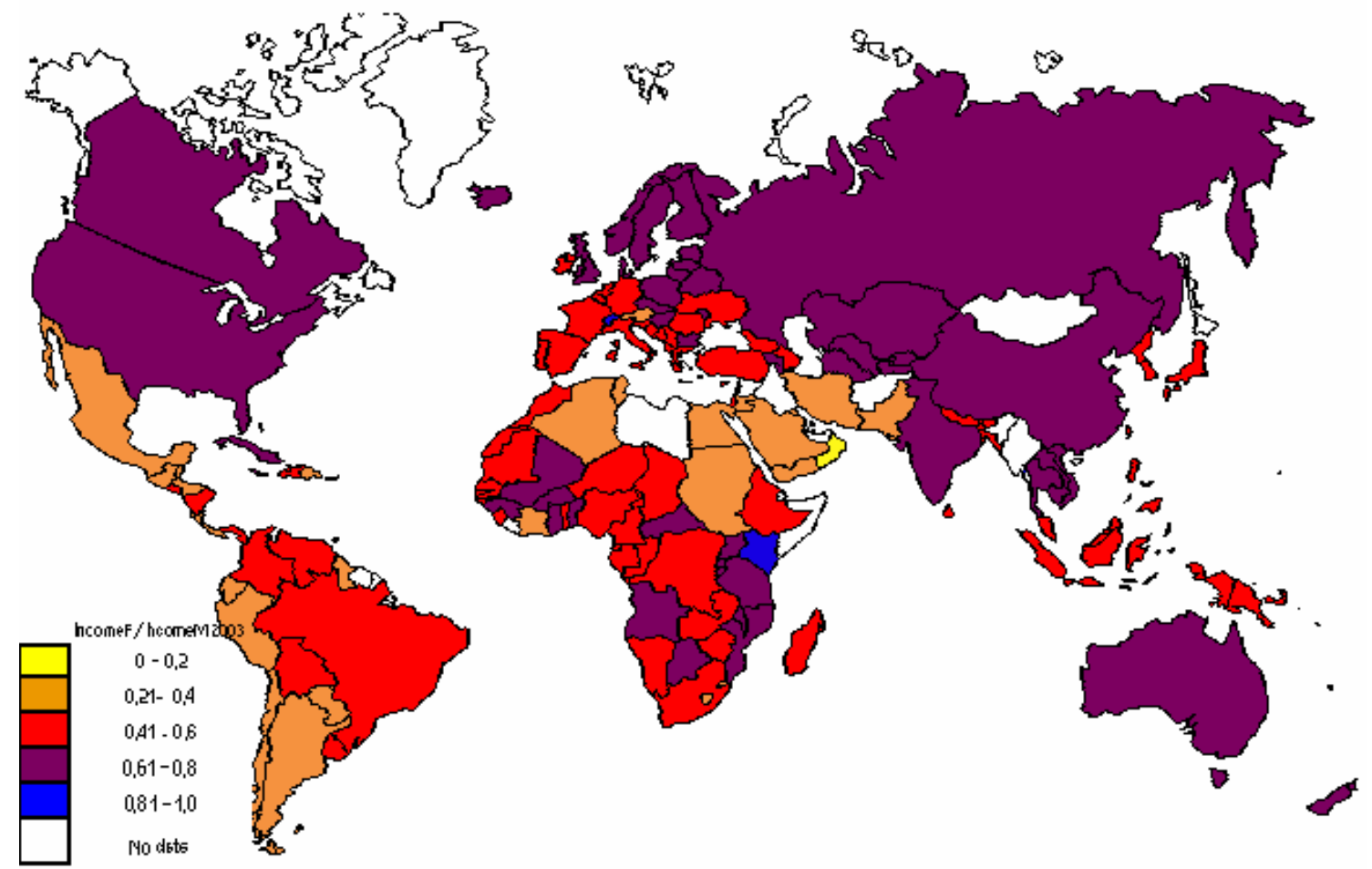

Data source: UN (2005): Human Development Report. 


\section{TABLE 6}

- EXPLAINING THE GENDER GAP.

- Dependent variable=log(ppp female earnings/ppp male earnings)

\begin{tabular}{|c|c|c|c|c|c|}
\hline - & & (1) & (2) & (3) & (4) \\
\hline - & Log per capita GDP & 0.0009 & -0.0228 & -0.00977 & -0.1752 \\
\hline - & & (0.0209) & (0.0208) & (0.0138) & (0.0155) \\
\hline - & Log female ec.act. & 1.0534 & 0.9619 & 1.0881 & 0.9739 \\
\hline - & & $(0.0958)^{* * *}$ & $(0.1002)^{* * *}$ & $(0.0897)^{* * *}$ & $k \quad(0.0986)^{* * *}$ \\
\hline - & Latin America & -0.1416 & -0.1685 & -0.07564 & -0.1658 \\
\hline - & & $(0.0520)^{* * *}$ & $(0.0579)^{* * *}$ & $* \quad(0.0542)$ & $(0.0529)^{* * *}$ \\
\hline - & East South Asia & 0.0807 & 0.0642 & 0.0917 & 0.1107 \\
\hline - & & $(0.0377)^{* *}$ & $(0.4545)$ & $(0.0369)^{* * *}$ & * $(0.0351)^{* * *}$ \\
\hline - & Log education ga & -0.02971 & & & \\
\hline - & (years spent sch) & $(0.0317)$ & & & \\
\hline - & Market openess & & 0.0407 & & \\
\hline - & & & $(0.3242)$ & & \\
\hline - & \%Indian & & & -0.0463 & \\
\hline - & & & & $(0.0023)^{* * *}$ & \\
\hline - & Log Wom in Govern & & & & 0.0614 \\
\hline - & & & & & $(0.03510)^{*}$ \\
\hline - & Constant & -4.5697 & -4.1010 & -4.5976 & -4.2743 \\
\hline - & & $(0.4230)^{* * *}$ & $(0.4311)^{* * *}$ & $(0.3504)^{* * *}$ & $(0.3765)^{* * *}$ \\
\hline - & $\mathrm{N}$ & 122 & 77 & 118 & 119 \\
\hline - & R-squared & 0.592 & 0.569 & 0.650 & 0.599 \\
\hline
\end{tabular}

Data source: UN(2005): Human Development Report. 


\section{BIBLIOGRAPHICAL REFERENCES:}

Alberto Alesina, A. Devleeschauwer, William Easterly, S. Kurlat, R. Wacziarg.

"Fractionalization". Mimeo. Harvard University, 2002.

Pau Baizan, Enriqueta Camps. "The impact of women's educational and economic resources on fertility. Spanish birth cohorts, 1901-1950". In Angelique Janssens (ed.) Gendering the Fertility Decline in the Western World, New York, 2007.

Robert J Barro, JW Lee. Sources of economic growth. Carnegie-Rochester Conference Series on Public Policy, Volume 40, June 1994, Pages 1-46

Robert J Barro, J-W Lee. "International Measures of Schooling. Years and Schooling Quality". American Economic Review. Papers and Proceedings. Vol. 86 No 2, pp. 218-23.

Robert Barro, J-W Lee. International Data on Educational Attainment. Updates and Implications. Working Paper. Harvard University. August 2000.

Gary S. Becker. "Quantity and Quality of Life and World Inequality", The American Economic Review, Vol .95, No. 1, (March 2005).

Gary S. Becker, Kevin M. Murphy, Robert F. Tamura Human Capital, Fertility, and Economic Growth Journal of Public Economics, October 1990

Gary S. Becker and Robert J. Barro A Reformulation of the Economic Theory of Fertility The Quarterly Journal of Economics, Vol. 103, No. 1 (Feb., 1988), pp. 1-25.

David E. Bloom and Jeffrey G. Williamson. Demographic Transitions and Economic Miracles in Emerging Asia. The World Bank Economic Review, 1998

David E. Bloom, Jeffrey D. Sachs, Paul Collier and Christopher Udry. Geography, Demography, and Economic Growth in Africa. Brookings Papers on Economic Activity, Vol. 1998, No. 2 (1998), pp.

Ester Boserup. Woman's Role in Economic Development. Hants. Gower Publishing CL, 1970.

John Brown, Timothy Guineanne (2002): Fertility Transition in a Rural Catholic Population: Bavaria 1880-1910", Population Studies, 56 vol 11, pp. 35-49.

J. C. Caldwell. Theory of Fertility Decline. New York. 1982.

Ansley J. Coale, Susan C Watkins (eds.). The Decline of Fertility in Europe. Princeton University Press, Princeton, 1986.

Jan De Vries. European Urbanization. London 1985.

Jean Dreze, Amartya Sen (2002): India: Development and Participation. 
Stanley Engerman, Kenneth L. Sokoloff (2002): "Factor Endowments, Inequality and Paths of Development Among New World Economies", Economia, Vol 3(Fall),pp.41-109.

Stanley Engerman, Kenneth L. Sokoloff (2006): "Colonialism, Inequality and Long-Run Paths of Development", in Banerjee,Benabou,Mookherjee (eds.), Understanding Poverty,Oxford,Oxford University Press,pp.37-61.

Robert W. Fogel. The Escape from Hunger and Premature Death, 1700-2100. Europe, America and the Third World. Cambridge University Press. Cambridge. 2004

Oded Galor and David N. Weil The Gender Gap, Fertility, and Growth The American Economic Review, Vol. 86, no 3 (Jun., 1996), pp. 374-387.

Claudia Goldin. Understanding the Gender Gap. Oxford. Oxford University Press, 1990.

Claudia Goldin. "The U shaped female labor force function in economic development and economic history" NBER WP no.4704, 1994.

R.A. Le Vine, S.E. Le Vine and others. "Women Schooling and Child Care in the Demographic Transition: A Mexican Case Study". Population and Development Review, Vol 17, No 3, 1991.

Alexander Moradi and Joerg Baten. Inequality in Sub-Saharan Africa: New Data and New Insights from Anthropometric Estimates. World Development. Volume 33, Issue 8, August 2005, Pages 1233-1265

Mark R. Rosenzweig and T. Paul Schultz. The Demand for and Supply of Births: Fertility and its Life Cycle Consequences. The American Economic Review, Vol. 75, No. 5 (Dec., 1985), pp. $992-$ 1015.

Jeffrey D. Sachs. The End of Poverty. Economic Possibilities for Our Time. Penguin Books. New York. 2005

Jeffrey D. Sachs. Common Wealth. Economics for a crowded planet. The Penguin Press. New York. 2008.

Amartya Sen. "More than 100 Million Women Are Missing". The New York Review, $20^{\text {th }}$ of December 1990.

Amartya Sen. "Missing Women. Social Inequality Outweighs Women's Survival Advantage in Asia and North Africa". British Medical Journal. Vol 304. $7^{\text {th }}$ of March 1992.

Amartya Sen. "Missing Women Revisited. Reduction in female mortality has been counterbalanced by sex selective abortions". British Medical Journal, $6^{\text {th }}$ of December 2 Xavier Sala-i-Martin. The World Distribution of Income. Falling Poverty and Convergence Period, Quarterly Journal of Economics, 2006.

Werner Troesken. Water, Race, and Disease, MIT Press, Cambridge Mass, 2004 
Jeffrey G. Williamson. "Demographic Change, Economic Growth and Inequality" in Nancy Birdsall, Allen C. Kelley, Steven W. Sinding (eds.): Population Matters. Oxford University Press, Oxford, 2001, pp. 106-135.

E. A. Wrigley (2004): Poverty, Progress and Population, Cambridge University Press, Cambridge.

E. A. Wrigley, Roger Schofield (1989): The population history of England, 1541-1871: a reconstruction, Cambridge University Press, Cambridge.

E. A. Wrigley, Roger Schofield (1997): English population history from family reconstruction, 1580-1837, Cambridge University Press, Cambridge. 
